ORIGINAL ARTICLE

\title{
Early surgery for appendicular lump in pediatric patients is still safe.
}

\author{
Nabi Bux Napar', Noor Ahmad Shaikh², Imamuddin Baloch ${ }^{3}$, Azhar Ali Shah $^{4}$, Bushra Shaikh ${ }^{5}$ Ishrat Mahtam ${ }^{6}$
}

Article Citation: Napar NB, Sheikh NA, Baloch I, Shah AA. Early surgery for appendicular lump in pediatric patients is still safe. Professional Med J 2022; 29(3):280-284. https://doi.org/10.29309/TPMJ/2022.29.03.6611

ABSTRACT... Objective: To analyze the outcomes of early surgical management of appendicular lump in pediatric patients. Study Design: Prospective Observational study. Setting: Department of Pediatric Surgery, Ghulam Muhammad Mahar Medical College Sukkur. Period: January 2019 to December 2020. Material \& Methods: Eighty seven patients of either gender with age up to 12 years, with diagnosis of appendicular lump were selected for this study. Variables that were analyzed include age, gender, presence of various symptoms, operative finding and difficulties, duration of surgery and duration of hospital stay. Results: Mean age of the patients was $8.22 \pm 2.35$ years. Out of 87 patients, $66(75.9 \%)$ were male and $21(24.10 \%)$ were female with male to female ratio of 3.14:1. Duration of surgery ranged from 47 to 142 minutes, with mean and standard deviation of $73.15 \pm 21.55$ minutes. Intra-operatively, perforated appendix was the most common finding as was seen in 39 (44.83\%) patients, followed by pus collection, which was found in 31 (35.62\%) patients, appendicular abscess was seen in $26(29.88 \%)$ patients whereas gangrenous appendix was found in $17(19.54 \%)$ patients. Difficulty in localizing appendix was faced in $13(14.94 \%)$ patients and difficulty in removal of adhesions was faced in $8(9.2 \%)$ patients. Post-operative complications were seen in $22(22.99 \%)$ patients. The duration of hospital stay ranged from 4 to 11 days with mean and standard deviation of $5.57 \pm 1.04$ days. Conclusion: It is concluded in our study that early surgery in children with of appendicular lump can safely be carried out with good outcome and shorter hospital stay.

Key words: Appendectomy, Appendicular Lump, Children, Early Surgery.

\section{INTRODUCTION}

Most common cause for abdominal surgery in pediatric population happens to be acute appendicitis. ${ }^{1,2}$ Signs and symptoms of this condition include loss of appetite, nausea, vomiting, abdominal pain which usually begins at umbilicus and then shifts in right iliac fossa, rebound tenderness, guarding and rigidity. Fever may or may not be present. ${ }^{3}$ Acute appendicitis poses a diagnostic challenge all over the world, in spite of the advancement in various diagnostic tools. ${ }^{4}$ Diagnosing Several scoring systems have been developed for confirmation of diagnosis and serve as a quick and cheap diagnostic tool for timely surgery and to reduce the rate of negative appendectomies. One of these score; Modified Alvarado Score is very popular (Figure-1). ${ }^{5,6}$

\begin{tabular}{|lll|}
\hline Symptoms/signs/investigations & \multicolumn{2}{l|}{ Score } \\
\hline Yes & No \\
\hline Symptoms & & \\
\hline $\begin{array}{l}\text { Migration of pain to right iliac } \\
\text { fossa }\end{array}$ & 1 & 0 \\
\hline Anorexia & 1 & 0 \\
\hline Nausea/Vomiting & 1 & 0 \\
\hline Signs & & \\
\hline Tenderness over right iliac fossa & 2 & 0 \\
\hline $\begin{array}{l}\text { Rebound tenderness over right } \\
\text { iliac fossa }\end{array}$ & 1 & 0 \\
\hline Temperature $>37.3^{\circ} \mathrm{C}$ & 1 & 0 \\
\hline Investigation & & \\
\hline Leucocytosis $>10 \times 10^{9} / \mathrm{L}$ & 2 & 0 \\
\hline Total score & 9 & 0 \\
\hline
\end{tabular}

Scoring system; Modified alvarado score;

Group-I 1-4 appendicitis unlikely.

Group-II 5-6 appendicitis possible.

Group-III 7-9 appendicitis definitive.

Figure-1. Modified alvarado score.

1. MBBS, FCPS, Assistant Professor Pediatric Surgery, Ghulam Muhammad Mahar Medical College Sukkur.

2. MBBS, FCPS, Professor Pediatric Surgery, Ghulam Muhammad Mahar Medical College Sukkur.

3. MBBS, FCPS, Associate Professor Surgery, Ghulam Muhammad Mahar Medical College Sukkur.

4. MBBS, FCPS, Associate Professor Surgery, Ghulam Muhammad Mahar Medical College Sukkur.

5. MBBS, FCPS, Assistant Professor Surgery, Ghulam Muhammad Mahar Medical College, Sukkur.

6. MBBS, FCPS, Assistant Professor Pediatric Surgery, Shaikh Zayed Hospital, Larkana.

\author{
Correspondence Address: \\ Dr. Nabi Bux Napar \\ Department of Pediatric Surgery \\ Ghulam Muhammad Mahar Medical College \\ Sukkur. \\ nabibux.napar@yahoo.com
}

Article received on:

24/05/2021

Accepted for publication:

$02 / 08 / 202$ 
Early diagnosis and timely surgery are keys to successful management of acute appendicitis. However, the classic picture of acute appendicitis may not be present in many patients. In pediatric population atypical presentation is very common. Acute appendicitis if untreated may result in formation of appendicular lump. Usually on 3rd or 4th day of acute appendicitis, inflamed appendix surrounded by bowel loops, greater omentum can be palpated as a lump in right iliac fossa. ${ }^{7}$ Around $2-4 \%$ cases of acute appendicitis result in formation of appendicular lump. ${ }^{8}$ In adult patients with acute appendicitis, the appendicular lump is well formed but in case of pediatric patients this doesn't happen, due to the fact that their greater omentum is not fully developed and does not give much assistance in walling off and limiting the spread of infection. ${ }^{9}$

The traditional treatment of appendicular lump which is mostly been followed in Pakistan is conservative management. This study was carried out in a hospital where most of the patients report from far-flung areas of rural Sindh, and many of those patients present with appendicular lump. The purpose of this study was to analyze the outcomes of surgical management of appendicular lump. The results of this study will help us choose the better management protocol for our population. Not many studies have been carried out on the surgical management of appendicular lump in pediatric patients of our region. Hence we planned to carry out this study.

\section{MATERIAL \& METHODS}

This prospective observational study was conducted at Pediatric surgery Department, Ghulam Muhammad Mahar Medical College Sukkur over the period of two years from 1st January 2019 to 31st December 2020. Permission was sought from the Ethical Review Board of the institute (GMMMC/Suk/Esst/Branch/117). Sample size was calculated with online sample size calculator available at https://www.calculator. net/sample-size-calculator.html. Sample size was estimated to be of 87 patients with $95 \%$ confidence level, $5 \%$ margin of error and population proportion of $6 \%$; as the reported complication rate of appendicular lump is $2-6 \% .10$ Patients of either gender with age up to 12 years, who reported in OPD or emergency department and were diagnosed with appendicular lump were recruited for the study. Written informed consent from the guardians of the patients was taken before recruiting them for the study. Those failing to give consent were excluded from the study. Patients with signs of peritonitis, septicemia and history of any chronic debilitating disease were also excluded from the study. Patients who were lost to follow up were also excluded from the study.

All patients were admitted in high dependency unit. Detailed history was taken and thorough physical examination was done. Name, age, gender, contact information and duration and frequency of symptoms including anorexia, nausea, vomiting, constipation, fever and abdominal pain were noted on a specially designed proforma. Lab investigations were carried out which included, complete blood count, urine DR, ultrasound abdomen, C-reactive protein, HBsAg and Anti- HCV. All patients were kept nil per oral. Maintenance fluid of $4 \mathrm{ml} / \mathrm{kg} / \mathrm{hour}$ and broad spectrum antibiotics were started. Monitoring of vital sings and urine output was started. Patients were shifted to operating room as soon as they were prepared for surgery. All cases were operated under general anesthesia. Duration of surgery, intra-operative findings and difficulties faced were noted on the proforma. Patients were kept in high dependency unit post-operatively. Post-operative complications including surgical site infection, post-operative adhesions, fecal fistula, respiratory tract infection and mortality etc. were recorded on the proforma. Duration of hospital stay was also noted for each patient. Patients were discharged once they tolerated the oral intake and had no post-operative complication or the post-operative complication was treated. Follow up of two months was carried out in all patients.

Data was analyzed with Statistical Package for Social Sciences analysis program (IBM-SPSS version 24). Mean and standard deviation was presented for quantitative variables like age, duration of symptoms, duration of surgery 
and duration of hospital stay. Frequency and percentage of qualitative variable like gender, symptoms and post-operative complications were computed.

\section{RESULTS}

Age range of the patients recruited for this study ranged from 3 to 12 years. Mean age of the patients was $8.22 \pm 2.35$ years. Age distribution is shown in Figure-2. Out of 87 patients, 66 (75.9\%) were male and $21(24.10 \%)$ were female with male to female ratio of $3.14: 1$. Details of duration of symptoms when patients reported in hospital are shown in Table-I. Details of presence of various symptoms in patients are given in Table-II below.

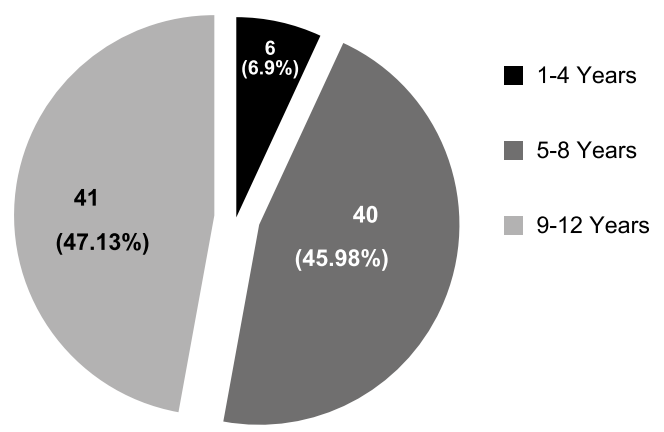

Figure-2. Age distribution.

\begin{tabular}{|l|c|}
\hline \multicolumn{1}{|c|}{ Duration in Days } & Number of Patients n (\%) \\
\hline $0-2$ & $09(10.34 \%)$ \\
\hline $3-4$ & $37(42.53 \%)$ \\
\hline $5-6$ & $33(37.93 \%)$ \\
\hline$\geq 7$ & $08(9.20 \%)$ \\
\hline \multicolumn{2}{|c|}{ Table-I. Number of days elapsed before patients } \\
presented in our hospital
\end{tabular}

Table-II. Patient symptomatology.

Duration of surgery ranged from 47 to 142 minutes, with mean and standard deviation of $73.15 \pm 21.55$ minutes. Intra-operatively, perforated appendix was the most common finding as was seen in 39 (44.83\%) patients, followed by pus collection, which was found in 31 (35.62\%) patients, appendicular abscess was seen in 26 (29.88\%) patients whereas gangrenous appendix was found in 17 (19.54\%) patients. Difficulty in localizing appendix was faced in 13 (14.94\%) patients and difficulty in removal of adhesions was faced in $8(9.2 \%)$ patients. Post-operative complications were seen in $22(22.99 \%)$ patients. Detailed analysis is shown below in Table-III. The duration of hospital stay ranged from 4 to 11 days with mean and standard deviation of $5.57 \pm 1.04$ days.

\begin{tabular}{|l|c|}
\hline \multicolumn{1}{|c|}{ Complication } & Number of Patients n (\%) \\
\hline Surgical Site infection & $09(10.34 \%)$ \\
\hline Fecal Fistula & $00(0 \%)$ \\
\hline Post-operative adhesions & $1(1.15 \%)$ \\
\hline Respiratory infection & $4(4.59 \%)$ \\
\hline Death & $00(00 \%)$ \\
\hline \multicolumn{2}{|c|}{ Table-III. Post-operative complications. } \\
\hline \multicolumn{2}{|c|}{} \\
\hline
\end{tabular}

\section{DISCUSSION}

Acute appendicitis and its sequelae in pediatric population pose a substantial amount of load on health care system all over the world. The overall incidence varies from 7 to 8 percent. ${ }^{11}$ Females tend to have less life time risk of developing acute appendicitis than males (6.7\% versus $8.6 \%) .{ }^{12}$ Timely diagnosis and surgery are the mainstay of the management. ${ }^{13}$ However, in a substantial number of patients the condition is not timely diagnosed, especially those belonging to rural areas of this country who have very limited health facilities. A number of these patients present in tertiary care hospitals with appendicular lump.

The choice between conventional conservative management and early surgical management of appendicular lump has remained a topic of debate for quite some time. The conventional conservative management regimen known as "Ochsner-Sherren regimen" introduced by a British surgeon named James Sherren; consists of hospitalization, vigilant monitoring, intravenous fluids, analgesics and antibiotics. Over 80 to 90 percent of the patients respond to this regimen 
and do not require surgical intervention; however 10 t0 20 percent require emergency surgery due to spreading infection. ${ }^{14}$

In our study, the mean age of the patients was $8.22 \pm 2.35$ years and duration of surgery ranged from 47 to 142 minutes with mean and standard deviation of $73.15 \pm 21.55$ minutes. Patients were predominantly male with male to female ratio of 3.14:1. All these result were comparable to the results of a similar study done by Rahman MA. ${ }^{15}$ Comparing the intra-operative findings of our study to above mentioned study; perforated appendix was the most common finding (44.83\% versus $77.73 \%$ ); followed by formation of pus (35.62\% versus $61 \%$ ).

In our study, difficulty in localizing appendix was faced in 13 (14.94\%) patients and difficulty in removal of adhesions was faced in 8 (9.2\%) patients. Comparable frequency of intra-operative difficulties was found in a study conducted by in a local study conducted at Department of Pediatric Surgery, National Institute of Child Health, Jinnah Sindh Medical University, Karachi, Pakistan by Israr $\mathrm{S}$ et al. ${ }^{16}$

The duration of hospital stay in our study ranged from 4 to 11 days with mean and standard deviation of $5.57 \pm 1.04$ days. Pandey $C$ et al. compared the length of hospital stay in conservatively and surgically managed patients. They found a significant difference; the average hospital stay in patients with early surgical was found out to be 4 days compared to 10 days those who were conservatively managed. ${ }^{17}$

The results of our study showed that appendicular mass can be successfully managed with early surgery with high success rate in children. Similar results were shown in a study carried out by Elsherbani R et al. They concluded that timely surgical intervention of appendicular lump is effective, safe and reliable method of management with good results a very low complication rate. ${ }^{18}$

The study carried out by Koirala A et al. showed contradicting results. They concluded in their study that with conservative approach, appendicular lump can be successfully managed. However, few patients may suffer complications, but those complications can also be successfully managed by surgical intervention. ${ }^{19}$ In another study, Elsaady $A$ et al. concluded that conservative management protocol is quite safe and effective with no significant surgical difficulties in patients who failed the conservative management. They further concluded that the rate of recurrence in patients successfully treated with conservative protocol is also low. ${ }^{20}$

Keeping all above findings in mind, it is suggested that early surgical intervention should be carried out in children presenting with appendicular lump. This approach is economical with lower rate of complications and decreases the duration of hospital stay.

\section{CONCLUSION}

It is concluded in our study that early surgery in children with of appendicular lump can safely be carried out with good outcome and shorter hospital stay.

Copyright@ 02 Aug, 2021.

\section{REFERENCES}

1. Stringer MD. Acute appendicitis. Journal of Paediatrics and Child Health. 2017; 53(11):1071-1076. doi:10.1111/ jpc.13737.

2. Swenson DW, Ayala RS, Sams C, Lee EY. Practical imaging strategies for acute appendicitis in children. American Journal of Roentgenology. 2018; 211:901909. 10.2214/AJR.18.

3. Dolgin SE, Beck AR, Tartter PI. The risk of perforation when children with possible appendicitis are observed in the hospital. The Journal of Emergency Medicine. 1993; 11(3):366. doi:10.1016/07364679(93)90072-f.

4. Kanumba ES, Mabula JB, Rambau P, Chalya PL. Modified Alvarado scoring system as a diagnostic tool for acute appendicitis at Bugando Medical Centre, Mwanza, Tanzania. BMC Surgery. 2011; 11(1). doi:10.1186/1471-2482-11-4.

5. Jain R, Kamble AM, Mitra RS. Use of modified Alvarado score in diagnosis of acute appendicitis: A prospective study. International Journal of Contemporary Medicine, Surgery and Radiology. 2018; 3(3):51-52. doi:10.21276/ijcmsr.2018.3.3.29. 
6. Srikanth S, Kumar TK, Lakshmi KS. A prospective observational study of role of modified Alvarado score, ultrasound abdomen and histopathology in the diagnosis of acute appendicitis. Journal of Medical Science And clinical Research. 2019; 7(6):1073-1079. doi:10.18535/jmscr/v7i6.180.

7. Patel, B, Patel K. A comparative study of appendicular lump management. International Surgery Journal. 2015; 2(2):235. doi:10.5455/2349-2902.isj20150521.

8. Chaudhary MK, Shankar M, Baruah TD, Ray R, Samal S. Laparoscopic management of appendicular lump. International Surgery Journal. 2020; 7(9): 3065. doi:10.18203/2349-2902.isj20203538.

9. Chowdhury MZ, Farooq MA, Rahman MA, Chowdhury TK. Management of early appendicular lump in children - laparoscopic technique versus open surgery: A comparative study in low-middle income country perspective. World Journal of Pediatric Surgery. 2020; 3(2):e000131. doi:10.1136/wjps-2020000131.

10. Bhandari R S, Thakur D, Singh K. Revisiting appendicular lump. Journal of Nepal Medical Association. 2010; 49(178):108-111. doi:10.31729/ jnma.108.

11. Almström M, Svensson JF, Svenningsson A, Hagel E, Wester T. Population-based cohort study on the epidemiology of acute appendicitis in children in Sweden in 1987-2013. BJS Open. 2018; 2(3):142-150. doi:10.1002/bjs5.52.

12. Snyder MJ, Guthrie M, Cagle S. Acute appendicitis: Efficient diagnosis and management. American Family Physician. 2018; 98(1):25-33. PMID: 30215950.

13. Wu J, Counihan T, Eko F, Ryb G, Drager L, Goldwater E. Ideal timing of surgery for acute uncomplicated appendicitis. North American Journal of Medical Sciences. 2013; 5(1):22. doi: 10.4103/19472714.106186.
14. Muhamed A, Bhat N. Acute appendicitis dilemma of diagnosis and management. The Internet Journal of Surgery. 2009; 23(2):1-10. doi:10.5580/18e0.

15. Rahman MA, Chowdhury TK, Chowdhury MZ, Farooq MA. Early appendectomy for appendicular mass: Operative findings and outcome in $\mathbf{2 2 0}$ children-a developing country perspective. Annals of Pediatric Surgery. 2020; 16(1):1-5. doi:10.1186/s43159-02000051-x.

16. Israr S, Akhtar J, Muhammad SR, Zamir N. Early surgical management of appendicular mass in pediatric patients. Journal of the College of Physicians and Surgeons Pakistan. 2021; 31 (03):302-306. https://doi. org/10.29271/jcpsp.2021.03.302.

17. Pandey C, Kesharwani R, Chauhan C, Pandey M, Mittra, P., Kumar, P., \& Raza, A. Management of appendicular lump: Early exploration vs conservative management. International Journal of Medical Science and Public Health. 2013; 2(4), 1046. https://doi.org/10.5455/ ijmsph.2013.230820131.

18. Elsherbani $R$, Alkhatrawi $T$. Appendicular mass in children: Our experience with early appendectomy. The Medical Journal of Cairo University. 2020; 88(12):2255-2260. https://doi.org/10.21608/ mjcu.2020.125314.

19. Koirala A, Thakur D, Agrawal S, Pathak KR, Bhattarai $M$, Sharma A. Appendicular mass: A conservative approach. Journal of Nobel Medical College. 2016; 5(2):47-50. https://doi.org/10.3126/jonmc.v5i2.16317.

20. Elsaady A. Management of appendicular mass; Comparative study between different modalities. AustinJournalofGastroenterology.2019;6(1):1-10https:// doi.org/10.26420/austinjgastroenterol.1097.2019.

\section{AUTHORSHIP AND CONTRIBUTION DECLARATION}

\begin{tabular}{|c|c|c|c|}
\hline No. & Author(s) Full Name & Contribution to the paper & Author(s) Signature \\
\hline 1 & Nabi Bux Napar & $\begin{array}{l}1,2,3,4 \\
\text { Concept designing, data }\end{array}$ & \\
\hline 2 & Noor Ahmad Shaikh & $\begin{array}{l}\text { collection, interpretation of } \\
\text { data, analysis drafting. }\end{array}$ & \\
\hline 3 & Imamuddin Baloch & & \\
\hline 4 & Azhar Ali Shah & & \\
\hline 5 & Bushra Shaikh & 5,6 & \\
\hline 6 & Ishrat Mahtam & $\begin{array}{l}\text { Designing interpretation of } \\
\text { data, analysis, drafting. }\end{array}$ & $\$$ \\
\hline
\end{tabular}

